\title{
Violência contra a mulher e políticas públicas
}

\author{
EVA A LTERMAN BLAY
}

\section{Violência de gênero: um problema mundial e antigo}

A GREDIR, matar, estuprar uma mulher ou uma menina são fatos que têm acontecido ao longo da história em praticamente todos os países ditos civilizados e dotados dos mais diferentes regimes econômicos e políticos. A magnitude da agressão, porém, varia. É mais freqüente em países de uma prevalecente cultura masculina, e menor em culturas que buscam soluções igualitárias para as diferenças de gênero. O rganismos internacionais começaram a se mobilizar contra este tipo de violência depois de 1975, quando a O N U realizou o primeiro D ia Internacional da M ulher. M esmo assim, a Comissão de Direitos H umanos da própria O N U , apenas há dez anos, na Reunião de Viena de 1993, incluiu um capítulo de denuncia e propõe medidas para coibir a violência de gênero.

No Brasil, sob o pretexto do adultério, o assassinato de mulheres era legítimo antes da R epública. Koerner mostra que a relação sexual da mulher, fora do casamento, constituía adultério - o que pelo livro V das OrdenaçõesFilipinas permitia que o marido matasse a ambos. 0 Código C riminal de 1830 atenuava 0 homicídio praticado pelo marido quando houvesse adultério. O bserve-se que, se o marido mantivesse relação constante com outra mulher, esta situação constituía concubinato e não adultério. Posteriormente, o Código Civil (1916) alterou estasdisposições considerando o adultério de ambos os cônjuges razão para desquite.

Entretanto, alterar a lei não modificou o costume de matar a esposa ou companheira.

\section{0 movimento feminista do fim do século $X I X$ e começo do século $X X$}

D esde a metade do século XIX até depois da Primeira Guerra M undial, 0 panorama econômico e cultural do Brasil mudou profundamente. A industrialização e a urbanização alteraram a vida cotidiana, particularmente das mulheres, que passaram a, cada vez mais, ocupar o espaço das ruas, a trabalhar fora de casa, a estudar etc. Vale a pena ler a análise de Susan Besse (1999) para se compreender o quanto essa transformação da infra-estrutura econômica, mais a alfabetização das mulheres, o cinema, os meios de transporte, a substituição de bens produzidos em casa pelos oferecidos pelas casas comerciais, alterou inteiramente o ritmo de vida e os contatos que as mulheres e homens passaram a desfrutar. Essas mudanças trouxeram o contato com comportamentos e valores de outros países, os 
quais passaram a ser confrontados com os costumes patriarcais ainda vigentes embora enfraquecidos.

D entre estas mudanças destacou-se a discussão sobre o casamento. M ulheres das classes média e alta, graças à educação e ao trabalho remunerado, adquiriram maior "poder social e econômico" (Besse, 1999, p. 41) e passaram a protestar contra a "tirania dos homens" no casamento, sua infidelidade, brutalidade, abandono - temas freqüentes entre escritoras, jornalistas e feministas dos anos de 1920 (Besse cita, entre elas, Cecilia Bandeira de M elo Rebêlo de Vasconcelos, que escrevia sob o pseudônimo de Chrisanthème, Elizabeth Bastos, I racema, A mélia de R esende $M$ artins, Andradina de $O$ liveira etc.) além das inúmeras leitoras da R evista Feminina. Já então se apontava que maridos tinham sido assassinados por mulheres brutalizadas (Besse, 1999, p. 46). A interpretação dessas queixas era traduzida como "crise" na família e o no casamento (Besse, 1999, p. 41) cujos responsáveis seriam o trabalho feminino e a paixão.

$\mathrm{N}$ aquela época, como hoje, afirmava-se que o trabalho feminino fora de casa provocava a desagregação da família. Daí o Estado ter incluído no Código Civil (1916), para proteger a família (mesmo a pobre), que a mulher deveria ter autorização do marido para poder trabalhar.

Q uanto ao casamento, reagia-se afirmando que era necessário retirar dele a romântica união por amor, substituindo-a pelo amor "civilizado", dotado de razão, excluindo a paixão, responsável pelos "crimes passionais sanguinários" (Peixoto apud Besse, 1999, p. 69).

O s crimes passionais, um dos mais graves problemas da época, constituíam uma verdadeira "epidemia" para al gumas feministas. Encabeçando o movimento contra estes crimes, Promotores Públicos como Roberto L yra, C arlos Sussekind de $M$ endonça, $C$ aetano Pinto de $M$ iranda $M$ ontenegro e Lourenço de $M$ attos Borges fundaram o Consel ho Brasileiro de $\mathrm{H}$ ygiene Social. Pretendiam coibir e punir os crimes passionais então tolerados pela sociedade e pela J ustiça. $N$ ão era propriamente a defesa das mulheres que eles visavam, mas pretendiam, efetivamente, proteger a instituição família (Besse, 1999, p. 90).

A atuação das mulheres nas décadas de 1920 e 1930, mais a ação dos Promotores Públicos e do J uiz $\mathrm{N}$ elson $\mathrm{H}$ ungria, apontam o gravíssimo problema do assassinato de esposas e companheiras, até hoje não resolvido, se é que não foi incrementado.

0 movimento dos Promotorese das feministas alcançou êxito relativo, embora 0 assassinato por amor continuasse a ocorrer e os assassinos a serem absolvidos.

\section{"Q uem ama não mata"}

U m forte movimento pela defesa da vida das mulheres e pela punição dos assassinos voltou a ocorrer na década de 1970, tendo seu auge após 30 de dezembro de 1976, quando Angela Diniz foi morta por Doca Street, de quem ela desejava se separar. 
A morte de Angela e a libertação de seu assassino levantaram um forte clamor das mulheres que se organizaram em torno do lema: "quem ama não mata". Pela segunda vez na história brasileira, repudiava-se publicamente que o amor justificasse 0 crime.

A costumado à subserviência conservadora, L ins e Silva, defensor de D oca, revelou seu espanto ante a extraordinária pressão popular que acompanhou o julgamento. 0 caso teve enorme repercussão não só no Brasil, mas também no exterior, havendo "publicidade nunca vista" sobre este caso, reclamou Lins e Silva (1991, p. 295). G rande controvérsia ocupou a imprensa (Blay, 2003) acirrando-se a polêmica contra os direitos humanos das mulheres. O s jornalistas Paulo F rancis e Tristão de Ataíde mostraram-se indignados contra as feministas e suas manifestações públicas que, segundo eles, pré-condenaram o réu; Lins e Silva (1991, p. 295) irritou-se com a repercussão que transformou uma "briga entre amantes em acontecimento nacional". Referiu-se ao "incidente" como se a vítima estivesse viva. O s prestigiados jornalistas e o advogado consideraram ilegítima a pressão da opinião pública nestes crimes contra mulheres justificados pelo amor.

D entre as matérias publicadas na época, artigo de Carlos H eitor Cony na revista Fatos eF otos- Gente, assim descrevia o crime:

eu vi o corpo da moça estendido no mármore da delegacia de Cabo Frio. Parecia ao mesmo tempo uma criança e boneca enorme quebrada... M as desde 0 momento em que vi o seu cadáver tiveimensa pena, não dela, boneca quebrada, mas de seu assassino, que aquele instante eu não sabia quem era (grifo meu).

O jornalista titubeia em sua opinião sobre o crime. De um lado, cita a Promotoria que acusava Street de libertinagem, cafetinagem, e conclui: "M as outros cafetões, outros libertinos e safados não se tornaram assassinos". Por outro lado, em benefício do assassino, Cony entrevista o delegado Sérgio Paranhos Fleury, que afirma "[...] o único crime respeitável, que não condenaria com rigor, era o passional... C rime passional qualquer um comete, até eu". Cony conclui: "A chamada privação de sentidos provocada pela paixão pode fazer do mais cordial dos homens um assassino".

\section{Ensinando a defender os que matavam "por amor"}

D entro do princípio inquestionável de que to dos têm direito a defesa, a culpa deve ser provada, ensina a academia como mecanismo da argumentação. 0 modelo paradigmático da didática de defesa dos assassinos " por amor" encontra-se no livro de Evandro L ins e Silva A defesa tem a palavra (1991). N ele, o jurista ensina os jovens advogados a defender um assassino, mesmo que confesso, e toma como modelo a defesa que ele próprio fizera de D oca Street, o assassino de Angela D iniz.

D oca Street matou Angela D iniz e confessou o crime al guns dias depois. Convivera com ela apenas três meses. A rgumentava a Promotoria (auxiliada pelo advogado Evaristo de M orais, contratado pela família de Angela), que ela não suportava mais sustentar um companheiro ciumento, agressivo e violento. De- 
pois dos poucos meses de conturbada convivência, durante os quais houve várias tentativas de rompimento, Angela mais uma vez mandou D oca sair de sua casa em Cabo Frio (Estado do Rio de Janeiro). Este fingiu se retirar da residência, arrumou as malas, colocou-as em seu automóvel mas, minutos depois retornou munido de uma Bereta. Perseguiu-a no banheiro e a matou com vários tiros, especialmente no rosto e no crânio.

A Promotoria descreve $D$ oca como pessoa que não trabalhava, sem endereço fixo, eque tivera várias mulheres, filhos dentro e fora do casamento, problemas criminais na juventude, homem violento e possessivo.

Como se contrapor ao perfil descrito pela Promotoria? Como demonstrar que $\mathrm{D}$ oca era pessoa absolutamente idônea, trabalhadora, bom pai, bom marido e com residência fixa?

O hábil defensor ensina, passo a passo, a construção desta imagem. São duas as principais estratégias. Primeiro era necessário demonstrar o bom caráter do assassino. Segundo, era importante denegrir a vítima, mostrar como ela o levara ao ato criminoso.

D oca, que não tinha profissão conhecida, passou a ser descrito como pessoa que vivia de comissões obtidas pela venda de letras de câmbio ou títulos para B ancos de I nvestimento. Bastaram uns três depósitos bancários para atestar esta fonte de renda. Q uanto a ter se relacionado com várias mulheres, isto não é negado, porém, afirma-se que elesó amara uma: Angela Diniz.

M as restava ainda uma pergunta: como foi possível que pessoa tão correta matasse uma mulher que conhecera há apenas três meses e pela qual nutria paixão tão fulminante? Como defender este impulso criminoso perante o Tribunal do J úri? Ensina Evandro Lins e Silva (1991, p. 27): "no Tribunal do Júri, o que se julga é o homem, muito mais do que o crime". C abe ao defensor, portanto, munir-se de todas as informações possíveis para defender seu cliente. 0 bom advogado deve penetrar nos sentimentos que o levaram a cometer o crime, e, para captar estas emoções, deve servir-se da literatura. E vandro conta ter se preparado lendo A servidão humana, onde reviu as "penas de Philip, sofrendo pelo amor da insensível M ildred". Para entender a rejeição sentida pelos amantes,

medi a extensão do martírio dos apaixonados repelidos pela mulher amada. R eli a defesa de Ferri, bela, magistral, do jovem chileno Carlo Cienfuegos, que matou em Roma a amante, Bianca $\mathrm{H}$ amilton, mulher fatal e sedutora, que o levou ao desvario, ao crime e à tentativa de suicídio... (Lins e Silva, 1991, p. 24).

Enfim, municiou-se para apresentar os sentimentos de rejeição, paixão, desvario, tudo o que pudesse comover o júri e levá-lo a inocentar o assassino da "mulher amada", cujo maior pecado era não aceitar tal amor.

$\mathrm{N}$ as escolas de Direito, ensina-se o mecanismo da preparação da defesa. $M$ as será que é dada a mesma ênfase aos direitos humanos das mulheres, dos pobres, dos e das negras e demais minorias? 


\section{As organizações não governamentais ( O N G s) feministas}

Ao longo das décadas de 1960 e 1970, feministas de classe média, militantes políticas contra a ditadura militar e intelectuais foram se somando a sindical istas e trabalhadoras de diferentes setores. Certamente, unia-as uma visão democrática e igualitária dos direitos da mulher que suplantava diferenças partidárias e ideológicas. Formou-se um vasto movimento unido de mulheres, se considerarmos que o inimigo era comum. (É claro que, em contrapartida, o movimento feminino conservador, ligado especialmente à igreja católica e ao movimento militar, também se organizou). Ao movimento feminista se aglutinou uma série de grupos que atuaram cotidianamente a favor dos direitos a melhores condições de vida, pela anistia, pela igualdade de direitos entre homens e mulheres. A formação de entidades voltadas a abrigar mulheres vítimas de violência doméstica não tardou a se formar. Por todo o Brasil grupos de ativistas, voluntárias, procuravam enfrentar todos os tipos de violência: estupros, maus tratos, incestos, perseguição a prostitutas, e infindáveis violações dos direitos humanos de mulheres e meninas. Diferentemente das décadas de 1910 e 1920, agora as denúncias destes crimes escondidos na e pela família tornaram-se públicos. Recebidos inicialmente com descrédito e sarcasmo pela mídia em geral, aos poucos foram reconhecidos (ver mais adiante essa transformação na imprensa escrita).

$M$ uito esforço custou às mulheres da sociedade civil arcar com esta fundamental atividade.

\section{Os C onselhos da C ondição Feminina e as D elegacias de D efesa da M ulher}

Com a anistia de 1979, a eleição direta de governadores em 1982 e a reorganização partidária, o cenário feminista se fortaleceu mas se segmentou em grupos partidários.

Para fazer frente às demandas de igualdade de gênero foi criado, em 1983, o primeiro Conselho Estadual da Condição Feminina em São Paulo. Em 1985, criou-se a primeira $\mathrm{D}$ elegacia de $\mathrm{D}$ efesa da $\mathrm{M}$ ulher, órgão eminentemente voltado para reprimir a violência contra a mulher ( $M$ assuno, 2002).

Concomitantemente, na sociedade civil, como já apontamos, vigoravam vários grupos feministas de apoio às mulheres vítimas. I ntenso trabal ho, quase sempre com escassos recursos e muito voluntariado, tentava suprir uma lacuna que agora, timidamente, começava a ser encampada pelo Estado.

N os anos anteriores, as mulheres que recorriam às D elegacias em geral sentiam-se ameaçadas ou eram vítimas de incompreensão, machismo e até mesmo de violência sexual. Com a criação das D elegacias de D efesa da M ulher (D D M ) o quadro começou a ser alterado. O serviço nas DDMs era e é prestado por mulheres, mas isto não bastava, pois muitas destas profissionais tinham sido socializadas numa cultura machista e agiam de acordo com tais padrões. Foi necessário muito treinamento e conscientização para formar profissionais, mulheres e 
homens, que entendessem que meninas e mulheres tinham o direito de não aceitar a violência cometida por pais, padrastos, maridos, companheiros e outros. E sta tarefa de reciclagem deve ser permanente, pois os quadros funcionais mudam e também os problemas.

Alterar essa relação de subordinação de gênero foi o início de uma revolução parcialmente bem-sucedida nos papéis sociais. O s crimes de gênero continuaram.

Cada vez mais estudos verificaram que não eram apenas maridos, mas outros parceiros também agrediam e matavam as mulheres sob os mais diversos pretextos.

\section{D ireitos humanos e homicídio de mulheres}

Em 1995, dei inicio à pesquisa sobre homicídio de mulheres para verificar como este crime era tratado: 1. pela mídia (especialmente jornais de 1991 e de 2000); 2. nos Boletins de 0 corrência das D elegacias de Polícia da capital de São Paulo (do ano de 1998); 3. nos Processos Judiciais, por meio de uma amostra representativa dos cinco Tribunais do Júri da Capital de São Paulo (de 1997). D esejava saber como a mídia, tão resistente a princípio, comportava-se na passagem do século XXI, o que os BO s registravam e como eram julgados os assassinos(as) de mulheres.

D iferentemente dos inúmeros estudos existentes, de excelente qualidade, esta pesquisa buscava investigar não apenas a chamada violência doméstica, mas os vári ostipos de homicídio - tentativa ou consumação - de mulheres de todas as faixas etárias.

Entre os resultados alcançados verificou-se:

Pelasnotícias de jornais

- M atam-se pessoas do sexo feminino de todas as idades, desde bebês até mulheres com mais de setenta anos. Prevalece a faixa compreendida entre 22 e trinta anos.

- O s jornais de 1991 indicavam que 22\% dos crimes eram motivados por tentativas de separação, ciúme, ou suspeita de adultério. Em 2000, estes mesmos motivos cresceram e foram responsáveis por $28 \%$ dos crimes.

- O filicídio, cometido por pais ou mães, não é raro no Brasil e nem em São Paulo. Em 1991, 8\% das meninas assassinadas tinham menos de dez anos; a percentagem é quase igual em 2000: 7\% Pais e mães nem sempre matam pelas mesmas razões. No caso das mães, o filicídio é atribuído, em geral, a dificuldades econômicas, abandono pelo pai da criança, a chamada e pouco conhecida depressão pós-parto, ou por vingança ao companheiro. No caso dos homens, o filicídio aparece, quase sempre, associado à vingança contra a mulher: um homem abandonado não se contenta em se vingar da companheira, ele mata também os(as) filhos(as) e eventualmente outras pessoas que tentam detê-lo.

- A "violência urbana" (balas perdidas, assaltos e sobretudo crimes em áreas de lazer) que, em 1991, era responsável por $17 \%$ dos crimes noticiados, reduziu-se relativamente, sendo substituída pelo aumento das ocorrências ligadas à droga (18\% em 2000). 
- O conteúdo do noticiário mostra uma clara tendência de mudança de linguagem. Se até a década de 1980 as vítimas eram apresentadas como causadoras de sua própria morte e havia um visível apoio aos assassinos - que seriam "levados" ao crime pela suposta conduta infiel da mulher ou por ela querer romper um relacionamento, na última década do século XX o noticiário se tornou mais investigativo, relativamente neutro e com certa tendência a questionar julgamentos que facilitavam a fuga dos réus.

- Destaco ainda que o espaço destinado a estas notícias, o local da publicação no jornal assim como aspectos da linguagem, refletem a classe social da vítima e do agressor.

\section{R ádio e tel evi são}

- Contraditoriamente, o rádio e a tel evisão continuam a reproduzir em seus programas musicais os antigos sucessos em que o homem mata a mulher que não mais quer a "felicidade" que ele Ihe proporcionava. Veja-se como exemplo a antiga e sempre tocada canção Cabocla Teresa (Raul Torres e J oão Pacífico) cujos versos cantam, sem remorso, o assassinato de Teresa:

Vancê, Tereza, descansa/ Jurei de fazer vingança/ Pra mordi de nosso amor $\mathrm{H}$ á tempos eu fiz um ranchinho/ Pra minha cabocla morar Pois era ali nosso ninho/ Bem longe desse lugar/ No alto lá da montanha Perto daluz do luar/ Vivi um ano feliz/ Sem nunca isso esperar E muito tempo passou/ Pensando em ser tão feliz/ M as a Tereza, dotô Felicidadenãoquis/ Pus meus sonhos nesse olhar/ Paguei caro meu amor Por mordi de outro caboclo/ Meu rancho ela abandonou/ Senti meu sangue ferver

Jurei a Tereza matar/ 0 meu alazão arriei/ E ela fui procurar/ Agora já me vinguei

É esse o fim de um amor/ Essa cabocla eu matei/ É a minha história dotô

Os programas televisivos, que dramatizam os crimes passionais, estupros seguidos de morte, incesto, trazem uma dupla mensagem: de um lado acusam o criminoso mas, ao mesmo tempo, romantizam esse tipo de crime. E sses veículos tendem a reproduzir a antiga versão de que a "vítima é responsável por sua morte" e, muitas vezes, ao reiterarem imagens e reconstituições dos supostos fatos exaltam os crimes.

Assim, o noticiário mostra um processo contraditório de mudança: ao mesmo tempo em que não mais se aceita o "matei por amor" noticia-se um incremento nos crimes que tem tais justificativas.

Boletins de ocorrência ( $\mathrm{BO}$ s)

Pesquisamos os Boletins de $O$ corrência (BO s) nas D elegacias G erais e não nas D elegacias de D efesa da M ulher pois estas, em razão da competência legal, estavam impedidas de registrar homicídios de mulheres até 1996. A Secretaria de Segurança recebe uma cópia de to dos os BO s, mas, ao divulgar suas análises estatísticas, não informa o sexo da vítima, uma grande dificuldade para o conheci- 
mento dos fatos que bem indica a desimportância das relações de gênero e a predominância de uma visão apenas masculina. Foi um longo e penoso trabalho separar, manualmente, dentre os milhares de BO s de 1998, aqueles em que havia vítimas femininas.

- Resultou o levantamento de 623 ocorrências com 964 vítimas, das quais 669 muIheres e 294 homens (em um BO o sexo não estava identificado). Entre as 669 vítimas mulheres, 285 eram vítimas de homicídio e 384 de tentativa de homicídio (ver notas).

- A análise dos BOs mostrou que, na metade das ocorrências, o(a) agressor(a) é desconhecido. Entre os identificados, quando a vítima é mulher, 90\%dos autores são homens.

- A maioria das vítimas - $62 \%$ - são mulheres brancas, $7 \%$ são negras e $30 \%$ pardas.

- Constatamos que a maioria tem alfabetização de nível primário (74\%), embora 14\% tenham o secundário e $3 \%$ o universitário.

- Confirmando os dados da imprensa, as vítimas estão na faixa etária dos 22 aos trinta anos.

- O perfil socioeconômico e etário dos agressores assemelha-se ao das vítimas.

- Apesar das inúmeras lacunas que os BO s apresentam, observou-se que cinco em cada dez homicídios são cometidos pelo esposo, namorado, noivo, companheiro, "amante" (sic). Se incluirmos ex-parceiros, este número cresce: em sete de cada dez casos as mulheres são vítimas de homens com os quais tiveram algum tipo de relacionamento afetivo. É marcante a dificuldade com que homens aceitem que a mulher rompa um relacionamento (cerca de dois em cada dez crimes são cometidos por ex-parceiros).

- Embora perdure a ideologia de que o lar é um lugar seguro, as relações familiares não são pacíficas: $12 \%$ dos homicídios ou tentativas são de responsabilidade do pai, mãe, filho, padrasto, sogra, ou seja, entre os agressores conhecidos, $66 \%$ são parentes da vítima feminina.

- Q ualquer instrumento serve para agredir - facas, ácido, fogo, madeira, ferro, além das próprias mãos - mas em sete de cada dez casos o revólver é usado.

\section{Processos Criminais nos Tribunais do Júri}

O s BO s, nos casos de homicídio e tentativa de homicídio, e depois I nquéritos Policiais - fase de instrução policial - quando encerrados são remetidos ao Poder Judiciário, onde nova fase de instrução será aberta para final julgamento. Para facilidade de compreensão, denomino Processo C riminal (PC) essa fase que se abre na J ustiça. A localização dos processos demandou cerca de dois anos de pesquisa, a partir do exame dos livros de registro dos Fóruns C riminais da Capital, e mais um ano e meio para localização e exame dos mesmos nos Tribunais do Júri da Barra Funda, Jabaquara, Santo A maro, Pinheiros e Penha. De um total de 8.805 processos, após procedimentos de seleção de uma amostra representativa, deveríamos analisar cem casos. Prevendo problemas, que de fato ocorreram, resultou uma amostra representativa de 81 Processos J udiciais. 
- Consistentemente com os achados anteriores, observamos que as vítimas são muIheres jovens, de 22 a trinta anos predominantemente, de cor branca, cuja escolaridade é 1 o grau incompleto, com profissão "não qualificada" originárias do Estado de São Paulo.

- Viviam em casas precárias de alvenaria ou apartamentos tipo conjunto habitacional, predominantemente na Zona L este.

- São solteiras, na maioria, têm filhos, sendo que uma em cada quatro tiveram filhos com os companheiros com quem viviam quando foram vitimadas.

- A penas 9\% destas vítimas tinham antecedentes criminais.

- Cerca de 2\% estavam grávidas quando foram assassinadas ou sofreram tentativa, fato que não impediu ou até motivou o crime.

- Agressores, mais do que vítimas, têm nível educacional de 1 o grau incompleto (33\% e 28\%) e estão na mesma faixa etária delas.

- Cerca de 5\% das vítimas têm nível universitário (completo ou não) o qual não aparece entre os réus, o que não deve ser interpretado literalmente mas merece cuidadosa análise. N ão estariam os criminosos de nível universitário entre os que fugiram?

- As informações contidas nos processos são muito incompletas: em 30\% dos casos não se tem informação sobre o nível educacional das vítimas, suas profissões, condição de moradia, antecedentes criminais e até mesmo se elas estavam grávidas ou não. Também não há informação se tinham filhos.

- Constatou-se que a maioria das vítimas (28\%) tinha profissão "não qualificada" seguidas pelas "do lar" (23\%). Cerca de 8\% eram estudantes de vários níveis. E ntre os réus, havia igual porcentagem de qualificados e não-qualificados (20\%), 10\% eram comerciantes. Praticamente não havia desempregados declarados.

- Os réus têm uma posição socioeconômica um pouco mais elevada do que as muIheres. D e modo geral, trata-se de uma população de baixa ou média renda.

- O bserva-se que em $50 \%$ dos casos o criminoso é desconhecido, o que, associado às informações da imprensa e aos Bos, permite sugerir que são homens de condição socioeconômica que lhes permite contratar advogados, fugir do flagrante e eventualmente nunca serem encontrados.

- E mbora haja inúmeras contradições entre as informações dos BO s e dos processos, observou-se consistência quanto à cor: em $50 \%$ dos casos a vítima era branca. $\mathrm{No}$ caso dos réus, a percentagem é um pouco menor (29\%) embora ainda predominem os brancos. Cerca de $36 \%$ das vítimas eram pardas e $1 \%$ negras. E ntre os réus, $21 \%$ eram pardose $8 \%$ negros. $\mathrm{N}$ um país de racismo oculto como o Brasil, em que se atribui quase sempre a responsabilidade da violência aos negros, estes dados vêm desmentir aquele preconceito.

- Q uase a metade das vítimas era solteira. U ma em cada quatro era casada legalmente. U ma em cada dez vivia junto a um companheiro. N ão importa o estado civil, portanto, todas tiveram um destino semelhante, foram vítimas de tentativa ou de homicídio.

- No caso dos réus, apenas um em cada quatro eram solteiros, 13\% eram casados e outros $13 \%$ tinham uma companheira. I sso indica que os réus eram casados mas não com as suas vítimas. 
Constatamos que, do total de processos enviados aos Tribunais e que não foram a Júri ou estão sem julgamento definitivo: $50 \%$ foram arquivados (basicamente porque os criminosos não foram identificados); $24 \%$ estão suspensos (porque o réu está foragido), em dois casos foram impronunciados (pois as provas eram insuficientes) e em três foram absolvidos.

A penas $14 \%$ dos réus foram julgados e condenados.

Em média, os processos não ficam muito tempo nos Tribunais: $46 \%$ ficam de um a dois anos. M as 0 andamento, o excesso de vezes que as testemunhas devem ser ouvidas, as possibilidades de idas e voltas certamente facilita a fuga dos réus e a perda de contato com as testemunhas.

O problema, então, não está na suposta morosidade da justiça, mas nos trâmites legais que deveriam ser mais ágeis e limitados. E m nome da ampla defesa dos réus certos setores dos aplicadores do D ireito subestimam a extensão e gravidade da violência praticada contra a mulher. É urgentíssima uma revisão do procedimento jurídico se quisermos, de fato, alterar a impunidade que cerca estes crimes, como expressaram vários juizes, promotores e advogados entrevistados.

\section{C onclusão}

H omicídios de mulheres fazem parte da realidade e do imaginário brasileiro há séculos, como mostra variada literatura de caráter jurídico, histórico, sociológico, revistas, notícias de jo rnal, além da dramaturgia, literatura de cordel, novelas de rádio e televisão, música popular, e a presente pesquisa. D epois de trinta anos de feminismo, que impôs à sociedade o "quem ama não mata" como repulsa ao assassinato justificado pelo "matar por amor" e de consistentes mudanças na posição socioeconômica e nos valores relativos à relação homem x mulher, como explicar que crimes de gênero continuem a ocorrer?

Reunindo-se os vários dados analisados, depreende-se que essa contradição perdura por várias razões, tais como: a persistente cultura de subordinação da mulher ao homem de quem ela é considerada uma inalienável e eterna propriedade; uma recorrente dramatização romântica do amor passional, sobretudo na tel evisão e no rádio, em que realidade e imaginário se retro-alimentam; na facilidade com que os procedimentos judiciais permitem a fuga dos réus; na pouca importância que as instituições do Estado dão à denúncia e ao julgamento dos crimes contra as mulheres e meninas.

Para enfrentar esta cultura machista e patriarcal são necessárias políticas públicas transversais que atuem modificando a discriminação e a incompreensão de que os $D$ ireitos das $M$ ulheres são $D$ ireitos H umanos. M odificar a cultura da subordinação de gênero requer uma ação conjugada.

Para isso é fundamental estabelecer uma articulação entre os programas dos $\mathrm{M}$ inistérios daJ ustiça, da E ducação, da Saúde, do Planejamento e demais ministérios.

Exemplo dessa desarticulação está na proposta de criação de mais $D$ elegacias de D efesa da M ulher, instrumento muito importante mas que tem de ser 
aparel hado em sua estrutura física, equipamento e ligação com as demais delegacias, com a Secretaria de Segurança, da J ustiça, da Educação e demais órgãos do governo estadual e federal. Assim como o pessoal desta importante instituição precisa ser treinado permanentemente, as D elegacias pouco podem fazer se não estiverem inseridas em um programa de transformação da cultura da força e da violência de gênero.

N os programas escolares - desde o ensino fundamental até o universitário precisa haver a inclusão da dimensão gênero mostrando como a hierarquia existente na cultura brasileira de subordinação da mulher ao homem traz desequilíbrios de todas as ordens - econômico, familiar, emocional e incrementa a violência. $M$ as a escola não pode ficar isolada de um processo amplo de transformação para alcançar a equidade de gênero. 0 que pode fazer uma professora, de qualquer nível da escala educacional, se ela própria é violentada? 0 que pode ensinar um professor que é um violador? 0 que pode fazer a escola se estiver desligada de um processo de transformação cultural?

Políticas públicas transversais visando ao mesmo objetivo - a equidade entre homens e mulheres - constitui um caminho para alterar a violência em geral e de gênero em particular. A Secretaria dos $D$ ireitos da M ulher pode desempenhar este papel articulador, associando-se aos Conselhos ou Secretarias da M uIher em todos os Estados.

D estaque-se, sobretudo, que um planejamento de políticas públicas transversais só funcionará com a total participação da sociedade civil.

N ota

A pesquisa teve de incorporar a complexidade dos $\mathrm{BO}$ s, pois eles podem conter mais de uma vítima, referir-se a uma chacina com diversas vítimas, conter vítimas dos dois sexos, de várias idades. Podem, também, incluir mulheres agressoras.

Referências bibliográficas

BESSE, Susan K. M odernizando a desigualdade São Paulo, Edusp, 1999.

BLAY, Eva Alterman "D ireitos humanos e homicídio de mulheres". Projeto de Pesquisa Integrada apoiado pelo CN Pq. Concluída em 2003. ainda não publicada. Resumo dos dados encontra-se na página do NEM GE (www.usp.br/ nemge).

CONY, Carlos H eitor em FatoseFotos- Gente. Brasília, 22 de outubro de 1979, o 948, ano XVII. Rio de Janeiro, Bloch Editores.

KOERNER, Andrei “Posições doutrinárias sobre direito de família no pós-1988. U ma análise política". Em FU KU I, Lia (org.). SegredosdeFamília. São Paulo, Annablume, 2002.

M ASSU N O, Elizabeth. "D elegacia de D efesa da M ulher: uma resposta à violência de gênero". Em BLAY, Eva A. I gualdade de opor tunidades para as mulheres. São Paulo, H umanitas, 2002. 
SI LVA, Evandro L. A defesa tem a palavra. 3a ed., Rio de Janeiro, Aide Editora, 1991.

O N U . World Conference on H uman Rights. Vienna 14-25 J une 1993. Vienna D eclaration and Programme of Action.

RESUmo - DifEREnTEMEnTE dos inúmeros estudos existentes, de excelente qualidade, esta pesquisa busca investigar não apenas a chamada violência doméstica mas os vários tipos de homicídio - tentativa ou consumação - de mulheres, de todas as faixas etárias. Ela investigou e procurou comparar como este crime era tratado: 1. pela mídia (especialmente jornais de 1991 e de 2000); pelo rádio e televisão; 2. nos Boletins de 0 corrência das D elegacias de Policia da capital de São Paulo (do ano de 1998); 3. nos Processos Judiciais, através de uma amostra representativa dos cinco Tribunais do J úri da Capital de São Paulo (de 1997). D esejava saber como a mídia tão resistente a principio se comportava na passagem do século XXI face à violência contra a mulher, o que os BO s registravam e como eram julgados os assassinos/ as de mulheres. O s complexos resultados obtidos revelaram mudanças em alguns segmentos e um concomitante mecanismo que retroalimenta a antiga violência nas relações sociais de gênero. Concluindo propõe-se a implantação de uma política transversal de gênero para enfrentar a violência.

A BSTRACT - UNLIKE numerous existing studies of excellent quality, this survey attempts to investigate not only domestic violence, as it is known, but also the various types of homicide - attempted or consummated - committed against women from all age groups. We investigated and endeavored to compare how this kind of crime was treated: 1. by the media - in particular, 1991 and 2000 newspapers, radio, and television; 2. in police reports filed in 1998 at precincts of the city of São Paulo; and 3. in judicial lawsuits, according to a representative sampling of the five jury courtrooms in the city of São Paulo in 1997. We sought to learn how the media, so resistant at first, dealt with violence towards women at the onset of the $21^{\text {st }}$ century, what the police reports recorded and how the murderers of women were sentenced. The complexity of our results reveals changes in certain segments and a simultaneous mechanism that feeds back and advances age-old violence in gender-based social relations. We conclude by propounding the implementation of transversal gender policy to counter this violence.

E va A Iterman Blay é professora titular de Sociologia na U SP e coordenadora científica do N emge ( $\mathrm{N}$ úcleo de Estudos da M ulher e R elações Sociais de G ênero).

A autora agradece especialmente ao presidente do Tribunal Superior, dr. N igro Conceição, que compreendeu o interesse da pesquisa e facilitou o trabal ho nos cinco Tribunais do J úri da capital de São Paulo. Agradece também o apoio obtido dos juízes presidentes dos Tribunais do Júri, dr. Claudio Emanuel Graciotto, dra. M aria Cristina Cotrose, dr. L uiz Tolosa N eto, dr. Camili Lellis dos Santos Almeida e dr. J oão Carlo Sá M oreita de O liveira. E à dra. Adriana Gragnani pela colaboração na seleção e orientação das bolsistas de D ireito e pela primeira leitura do resumo. E ao CN Pq pelo apoio integral.

Texto recebido e aceito para publicação em 15 de setembro de 2003. 